\title{
PENGEMBANGAN MODUL KEWIRAUSAHAAN BAGI TENANT \\ INKUBATOR BISNIS: PENDEKATAN MODEL ANALYSIS DESIGN \\ DEVELOPMENT IMPLEMENTATION EVALUATION (ADDIE)
}

\author{
Amelia Hidayah ${ }^{1}$ \\ amelia.hidayah@trilogi.ac.id \\ Fanny Suzuda Pohan ${ }^{2}$ \\ fannysuzuda.pohan@trilogi.ac.id
}

\begin{abstract}
University business incubator has become a place for many entrepreneurs to develop innovative products. However, several problems are experienced by tenants including capital, lack of business ability, poor of performance teams. Facing tenant problems related lack of business ability can be overcome by training and coaching. Therefore, researchers try to develop entrepreneurship modules for university business incubators. The research applies ADDIE (Analyzing, Designing, Developing, Implementation, and Evaluation) model. There are five major phases that are carried out starting from identifying training topics, designing a module, creating modules and questionnaires, providing entrepreneurship training, and evaluating modules. After going through 5 stages, the research produces 3 entrepreneurship modules, namely business models, financial understanding, and winning markets through digital marketing. These three modules are delivered in training activity which are divided into three sessions. After attending training, the participants respond that the modules are structured in terms of content and their benefits in improving management skills.
\end{abstract}

Keywords: entrepreneurship module, business incubator, ADDIE model 


\section{PENDAHULUAN}

Indonesia mengalami pertumbuhan ekonomi selama satu dekade terakhir, ratarata 5\% per tahun. Data ini menunjukkan Indonesia tengah bersiap untuk menjadi negara berpendapatan menengah tahun 2025. Salah satu sektor yang perlumendapatkan perhatian serius dari pemerintah adalah sektor kewirausahaan. Hingga saat ini, pertumbuhan sektor kewirausahaan di Indonesia masih tertinggal jauh jika dibandingkan dengan negara Asean lainnya. Kementrian Perdagangan, berdasarkan data dari Entrepreneurship Global Index 2018 menyatakan bahwa sampai dengan tahun 2018, indeks kewirausahaan Indonesia hanya sebesar $3.1 \%$. Sedangkan indeks kewirausahaan di negara maju sebesar 14\%. Data lain menyatakan kewirausahaan Indonesia berada di peringkat 94, di bawah Vietnam dan Thailand. Dengan mengetahui data-data tersebut, hendaknya pemerintah bersama-sama dengan perusahaan-perusahaan, institusi pendidikan, masyarakat, dan organisasi lain membangun ekosistem bisnis kewirausahaan yang tersistem dengan baik, transparan, dan jelas.

Salah satu organisasi yang berkontribusi dalam mencetak wirausaha adalah perguruan tinggi. Peran perguruan tinggi adalah mengembangkan hard skills melalui ilmu pengetahuan dan seni dan soft skills melalui sistem kurikulum yang melibatkan kerja sama, integritas, pemecahan masalah, dan norma-norma lainnya. Kurikulum yang dikembangkan harus berorientasi kepada perkembangan industri.

Program yang digagas oleh perguruan tinggi adalah inkubator bisnis teknologi. Program ini sejalan dengan Pemerintah untuk melahirkan wirausaha berbasis teknologi. Agustina (2011) menjelaskan layanan inkubator bisnis dibagi menjadi lima: service, memberikan bimbingan dan konsultasi manajemen seperti pemasaran, keuangan, produksi, teknologi dan sebagainya, support yaitu dukungan pengembangan usaha dan akses penggunaan teknologi, skill development yaitu pelatihan penyusunan rencana usaha (business plan) dan pelatihan manajemen lainnya, seed capital yaitu menyediakan dana awal usaha serta upaya memperoleh akses permodalan kepada lembaga-lembaga keuangan, synergy yaitu menciptakan jaringan usaha lokal maupun internasional. Kemenristekdikti menyatakan jumlah inkubator bisnis perguruan tinggi masih sangat sedikit. Dari 4.600 perguruan tinggi di Indonesia, baru berdiri 48 inkubator bisnis perguruan tinggi negeri dan 32 inkubator bisnis perguruan tinggi swasta. Hal ini menjadi sangat disayangkan ketika fokus perguruan tinggi yaitu Tridharma perguruan tinggi (Pengajaran, Penelitian, dan Pengabdian) dan salah satu luaran berupa hasil penelitian. Katz menyatakan perguruan tinggi adalah pusat ilmu pengetahuan dan pembangunan manusia yang berorientasi pada inovasi, kewirausahaan, dan produktivitas (Naderi, et., al., 2013). Perguruan tinggi hendaknya mempersiapkan mahasiswa untuk beradaptasi dengan cepat dalam komunitas (Ganefri \& Hidayat, 2013). Melalui inkubator bisnis, perguruan 
tinggi hendaknya mengembangkan hasil penelitian yang mempunyai potensi untuk bisa dikomersialisasi di pasar.

Pemerintah terus mendorong perguruan tinggi untuk membangun inkubator bisnis teknologi (IBT) yang melahirkan perusahaan pemula (start-up) atau tenant berbasis teknologi. Konsep dalam IBT sendiri adalah bagaimana membangun jejaring bisnis antara tenant (sebutan bagi pelaku usaha), pemerintah, perusahaan, dan akademisi atau yang disebut dengan triple helix. Mengingat isu-isu yang terjadi pada tenant diantaranya market driven mismatch (ketidak sinkronan antara pasar dengan produk yang ditawarkan), lack of management skills (tenant kurang memiliki kemampuan dalam menjalankan bisnis), lack of access to capital (tenant tidak memiliki akses untuk memperoleh modal). Isu inilah yang bisa menyebabkan banyak tenant gagal di tahap awal.

Untuk meningkatkan kompetensi manajemen bisnis para tenant maka IBT memberikan pelatihan-pelatihan bisnis. Tujuan pelatihan bisnis adalah menumbuhkan semangat kewirausahaan, analisa kebutuhan, peluang pasar, perencanaan bisnis, studi kelayakan, manajemen produksi, manajemen sumber daya manusia, pemasaran, dan pengembangan bisnis. Inovasi yang berkelanjutan, pengembangan dan penelitian mengenai pendidikan kewirausahaan dan usaha dalam meningkatkan semangat kewirausahaan adalah upaya-upaya yang dilakukan untuk menekan angka pengangguran berpendikan tinggi (Mason, 2011; Nyello, Kalufya, Rengua, Nsolezi, \& Ngirwa, 2015; El-Gohary, Selim, and Eid, 2016; Rodríguez, \& Wise, 2016; Hynes, Kennedy, \& Pettigrew, 2016; Bell, and Bell, 2016; Zeng, \& Honig, 2016; Loi, Castriotta, \& Di Guardo, 2016; Suna Lowe Nielsen William B. Gartner, 2017; January P. Warhuus, Lene Tanggaard, Sarah Robinson, Steffen Moltrup Erno, 2017).

Keberhasilan dalam proses pembelajaran kewirausahaan ditentukan dari pemilihan media pembelajaran (Smaldino, 2012). Media pelatihan bisnis yang relevan dalam menunjang pembelajaran kewirausahaan adalah modul. Modul merupakan sumber yang berisi materi, metode, bersifat terbatas, dan disusun secara sistematis dan menarik (Vinokurova, Krivdina, Badin, and Efimova, 2016; Hasanah, Malik, and Dirawan Darma, 2016). Modul dipilih sebagai media pembelajaran karena mempunyai karakteristik yaitu sederhana dan praktis, aplikatif, dilengkapi dengan tugas, contoh kasus, atau proyek, stand-alone karena tidak bergantung dengan media lain. Modul bisa ditingkatkan menjadi lebih atraktif dengan mengkombinasikan media pembelajaran lain seperti video.

Penelitian ini memfokuskan kepada penyusunan modul kewirausahaan bagi tenant inkubator bisnis perguruan tinggi dengan menggunakan model ADDIE. Modul ini diharapkan dapat meningkatkan kompetensi tenant dalam manajemen bisnis. 


\section{TINJAUAN PUSTAKA}

\section{Desain Instruksional}

Aldoobie (2015) menjelaskan desain instruksional disebut juga dengan teknologi instruksional. Desain instruksional adalah pendekatan melalui proses sistematis yang membantu dalam menciptakan dan mengembangkan bahan ajar yang efektif, menarik, dan efisien dengan menggunakan seni, ilmu pengetahuan, pembelajaran, dan teori pengajaran. Didalam penyusunan desain instruksional melibatkan kegiatan analisa kebutuhan dan permasalahan, merancang materi dan aktivitas-aktivitas, perumusan tujuan menjadi hal yang penting agar kebutuhan pengajar, implementasi termasuk pelatihan tercapai. Didalam praktiknya, terdapat model desain intruksional yang secara sistematis berperan didalam pengembangan pelatihan. Model tersebut dikenal dengan nama ADDIE.

\section{Model ADDIE}

Model ADDIE adalah pendekatan instruksional yang dapat membantu perancang instruksional, pengembang konten, maupun guru untuk menghasilkan desain instruksional pengajaran yang efektif dan efisien. Model ADDIE bisa dipakai dengan berbasis online atau tatap muka langsung. ADDIE merupakan singkatan dari proses yang terdiri dari Analysis, Design, Development, Implementation, dan Evaluation. Dalam model ADDIE, setiap proses saling terhubung antara satu proses dengan proses selanjutnya.

\section{Fase Analysis}

Pada tahap awal ini, perancang instruksional melakukan empat kegiatan analisa, analisa peserta, analisa tujuan instruksional, pengembangan analisis pembelajaran, dan analisa tujuan pembelajaran. Dalam menganalisa peserta, perancang harus menggali informasi sebanyak mungkin dari peserta apakah pernah mempelajari topik yang akan diberikan sehingga perancang mendapat gambaran jelas mengenai tema yang akan diberikan dan menyusun rencana pembelajaran dengan baik. Untuk menggali informasi dari peserta, perancang dapat melakukan survei, wawancara, maupun tes pengetahuan. Analisa tujuan instruksional adalah kegiatan perancang dalam mengidentifikasi tujuan untuk topik tertentu. Identifikasi tujuan menjelaskan lebih lanjut poin-poin pelatihan apa yang akan diberikan kepada peserta. Kegiatan ketiga yang dilakukan perancang adalah pengembangan analisa pembelajaran dimana perancang merumuskan langkah-langkah penting berdasarkan tujuan pembelajaran yang telah disusun sebelumnya. Kegiatan terakhir yang dilakukan adalah mengembangan tujuan pembelajaran. Pada kegiatan ini perancang harus bisa merumuskan apa yang diharapkan dari peserta setelah mempelajari satu topik tertentu. Perumusan tujuan pembelajaran ini harus memperhatikan aspek keterampilan, prilaku, dan pengetahuan. Perumusan tujuan 
ini harus spesifik dan terukur sebagai indicator ketercapaian tujuan pembelajaran. Sebagai contoh, perancang dapat menuliskan tujuan pembelajaran dengan cara ini, pada akhir pelatihan, peserta dapat memahami topik tertentu minimal $85 \%$.

\section{Fase Design}

Tahap design berkaitan dengan proses memfasilitasi proses pembelajaran dan proses interaksi menjadi mudah. Fase design meliputi desain penilaian untuk topik pelatihan, pemilihan bentuk pelatihan, dan merumuskan strategi pengajaran. Pada fase desain penilaian topik, perancang sebaiknya memberikan penilaian dengan data yang telah didapatkan pada fase analysis, sesuai dengan topik pelatihan. Sebaiknya perancang tidak memberikan penilaian yang keluar dari konten pelatihan karena dapat menimbulkan kesalahpahaman. Kegiatan desain selanjutnya adalah pemilihan bentuk pelatihan. Kegiatan ini adalah menentukan media apa yang akan dipergunakan pengajar dalam menyampaikan materi kepada peserta. Banyak media yang dapat dipilih misalnya pelatihan di dalam ruangan, tatap muka online melalui internet, buku kerja, modul, dan lain-lain. Dalam pemilihan media pelatihan hendaknya menyesuaikan dengan kegiatan penilaian. Contohnya apabila peserta akan mengikuti tes dengan menggunakan laptop mereka sendiri, cara efektif kemudian adalah memilih bentuk pelatihan yang memungkinkan peserta untuk menggunakan laptop sendiri. Kegiatan terakhir dalam fase ini adalah merumuskan strategi pembelajaran dimana pengajar merumuskan metode alternatif pembelajaran yang dapat digunakan misalnya ceramah, diskusi, studi kasus, latihan, dan lain-lain.

\section{Fase Development}

Keberhasilan fase ini bergantung dari kedua fase sebelumnya, analysis dan design. Apabila kedua fase sudah dilakukan dengan tepat, maka fase development akan mudah dikerjakan. Pada fase ini ada beberapa kegiatan yang dilakukan yaitu membuat materi awal sebagai bagian dari keluaran kegiatan yang dilakukan. Materi awal ini disirkulasikan di anggota tim kecil untuk mendapatkan respon terkait perbaikan, kekurangan-kekurangan, ataupun penambahan materi. Anggota projek pun harus diminta masukan-masukan sehingga materi awal dapat dikembangkan ke tingkat yang lebih tinggi lagi. Setelah kita mengumpulkan masukan-masukan terhadap materi dan mempertimbangkannya, kegiatan selanjutnya adalah mengembangkan materi. Hal-hal yang perlu dipertimbangkan dalam pengembangan materi adalah tujuan yang ingin dicapai, kedalaman konten berdasarkan masukan dari anggota tim dan peserta, serta perkembangan topik materi terhadap keilmuan dan industri. Setelah kita mengecek materi dengan detil untuk memastikan kualitas materi yang akan disajikan kepada peserta, maka kegiatan berikutnya adalah menguji coba materi pelatihan dalam satu kelompok kecil dengan mengkondisikan seperti kegiatan sesungguhnya. Selain itu juga perlu dipersiapkan evaluasi dari materi untuk mendapatkan masukan, saran, atau 
perbaikan.

\section{Fase Implementation}

Pada fase ini adalah menterjemahkan timeline kegiatan pelatihan yang telah dibuat kedalam kegiatan pelatihan. Dalam fase ini ada tiga kegiatan yang harus dilakukan, pelatihan kepada instruktur atau pengajar. Bekerja untuk melatih instruktur adalah proses yang sangat penting dalam fase implementation karena kadang-kadang orang yang sedang berlatih bukanlah orang yang menciptakan bahan ajar. Kegiatan berikutnya adalah mempersiapkan peserta untuk instruksi yang telah dibuat. Peserta didik harus dipastikan memiliki semua bahan, alat, dan pengetahuan untuk berkontribusi pada kursus atau kelas. Kegiatan terakhir dalam fase implementation adalah mempersiapkan lingkungan belajar. Instruktur perlu menyiapkan semua bahan yang dibutuhkan untuk mengirimkan konten seperti spidol atau cek. Jika instruktur siap dengan semua detail ini mereka akan fokus hanya dalam menyampaikan konten dan pengalaman.

\section{Fase Evaluation}

Proses terakhir dalam model ADDIE adalah fase evaluation. Sangat penting untuk mengevaluasi setiap langkah yang harus dilakukan untuk memastikan kesesuaian antara desain instruksional dan bahan-bahan dalam memenuhi kebutuhan pelajar. Selain itu, ketika berbicara tentang evaluasi, maka terdapat dua jenis evaluasi, yaitu evaluasi formatif dan evaluasi sumatif. Pertama, evaluasi formatif adalah proses berkelanjutan yang dilakukan pada saat pengerjaan bahan ajar di setiap fase pada model ADDIE. Ada tiga proses dasar evaluasi formatif, yaitu satu banding satu, kelompok evaluasi kecil, dan uji coba di lapangan. Ketika proses evaluasi berlangsung, dapat memilih peserta yang memiliki fitur yang mirip dengan pembelajar sebenarnya dan mengevaluasi materi berdasarkan itu.

\section{METODE PENELITIAN}

Selama proses penelitian, peneliti memformulasikan tahapan-tahapan penelitian sebagai berikut. 


\section{Gambar 1}

Tahapan Penyusunan Modul Dengan Model ADDIE

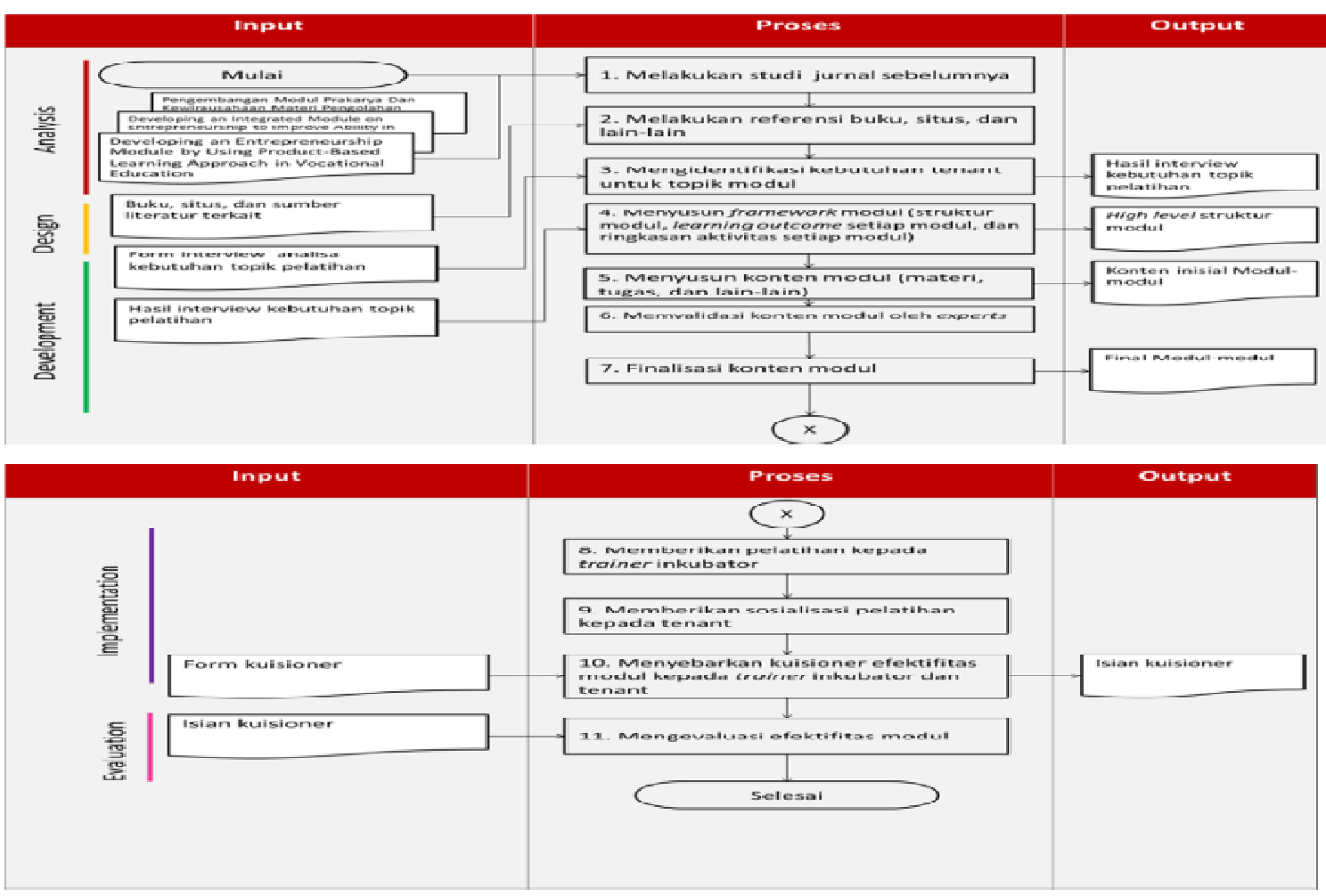

Sumber: Data diolah

\section{HASIL DAN PEMBAHASAN}

\section{Tahap 1 Analysis}

Pada tahap analysis, peneliti melakukan beberapa kegiatan antara lain mengidentifikasi topik pelatihan tenant berdasarkan pengalaman peneliti yang menjadi manajer inkubator bisnis Trilogi dan mengadakan wawancara mendalam dengan 3 inkubator bisnis swasta dan 2 perguruan tinggi dengan tujuan studi banding, menggali informasi mengenai kurikulum pelatihan bisnis beserta konten yang disajikan. Dari kegiatan wawancara diperoleh informasi mengenai inkubator dan pelatihan yang telah dirangkum sebagai berikut: 
Tabel 1 Topik Pelatihan Inkubator Bisnis

\begin{tabular}{|c|c|c|c|}
\hline $\begin{array}{l}\text { Inkubator } \\
\text { Bisnis }\end{array}$ & Portofolio Inkubator & Pelatihan & $\begin{array}{l}\text { Masukan } \\
\text { Wawancara }\end{array}$ \\
\hline $\begin{array}{l}\text { Perguruan } \\
\text { Tinggi } \\
\text { Swasta A, } \\
\text { Jakarta }\end{array}$ & $\begin{array}{l}\text { - Pendanaan didapatkan } \\
\text { dari hibah } \\
\text { Kemenristekdikti } \\
\text { - Inkubator } \\
\text { memfokuskan pada } 3 \\
\text { bidang tenant yaitu } \\
\text { Food, Agriculture and } \\
\text { Health, Information and } \\
\text { Communication } \\
\text { Technology, dan Design } \\
\text { and Creative Products. } \\
\text { - Fase inkubasi meliputi } \\
\text { pra-inkubasi, inkubasi, } \\
\text { dan pasca inkubasi. } \\
\text { - Inkubator tidak } \\
\text { memiliki peta } \\
\text { kurikulum. } \\
\text { - Inkubator menyusun } \\
\text { materi pelatihan per } \\
\text { kegiatan inkubasi. }\end{array}$ & 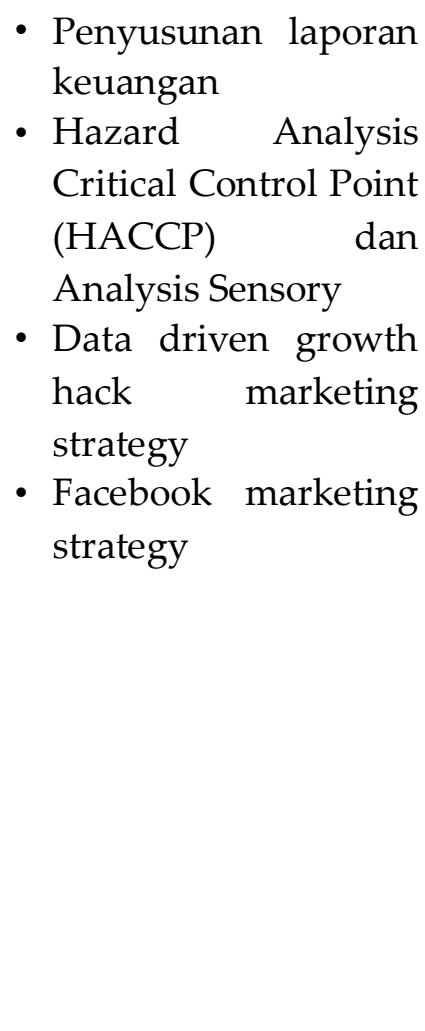 & $\begin{array}{l}\text { - Inkubator harus } \\
\text { memiliki desain } \\
\text { kurikulum yang } \\
\text { dapat } \\
\text { disesuaikan } \\
\text { dengan tren } \\
\text { bisnis dan bisnis } \\
\text { tenant }\end{array}$ \\
\hline $\begin{array}{l}\text { Perguruan } \\
\text { Tinggi } \\
\text { Negeri B, } \\
\text { Depok }\end{array}$ & $\begin{array}{l}\text { - Pendanaan didapatkan } \\
\text { dari PAUI, } \\
\text { Kemenristekdikti, dan } \\
\text { Kerjasama dengan } \\
\text { mitra. } \\
\text { - Fokus bidang tenant } \\
\text { Food, Agriculture and } \\
\text { Health, Information and } \\
\text { Communication } \\
\text { Technology } \\
\text { - Fase inkubasi meliputi } \\
\text { pra-inkubasi, inkubasi, } \\
\text { dan pasca inkubasi. } \\
\text { - Kurikulum terbagi }\end{array}$ & $\begin{array}{l}\text { Materi digital: Idea to } \\
\text { startup, Building } \\
\text { Minimum Viable } \\
\text { Brand, Product } \\
\text { Development } \\
\text { Design Sprint, Team } \\
\text { Management, Talent } \\
\text { Management, } \\
\text { Fundraising } \\
\text { Materi non-digital: } \\
\text { Brand Essence, } \\
\text { Startup Matrix, } \\
\text { Integrated } \\
\text { Promotion, Business }\end{array}$ & $\begin{array}{l}\text { - Penambahan } \\
\text { materi meliputi } \\
\text { model bisnis } \\
\text { dengan alat } \\
\text { bantu Business } \\
\text { Model Canvas, } \\
\text { Fundraising, } \\
\text { Hukum } \\
\text { (dokumen legal } \\
\text { pengurusan } \\
\text { perusahaan) }\end{array}$ \\
\hline
\end{tabular}




\begin{tabular}{|c|c|c|c|}
\hline $\begin{array}{l}\text { Inkubator } \\
\text { Bisnis }\end{array}$ & Portofolio Inkubator & Pelatihan & $\begin{array}{l}\text { Masukan } \\
\text { Wawancara }\end{array}$ \\
\hline & $\begin{array}{l}\text { menjadi } 2 \text {, digital dan } \\
\text { non digital. }\end{array}$ & $\begin{array}{l}\text { Compas, Sales } \\
\text { Acceleration, Profit } \\
\text { Acceleration, } \\
\text { Building solid team }\end{array}$ & \\
\hline $\begin{array}{l}\text { Swasta A, } \\
\text { Jakarta }\end{array}$ & $\begin{array}{l}\text { - } \text { Pendanaan didapatkan } \\
\text { dari Bursa Efek } \\
\text { Indonesia. } \\
\text { - Inkubator } \\
\text { memfokuskan pada } \\
\text { digital based startup } \\
\text { yang siap melakukan } \\
\text { IPO. } \\
\text { - Inkubator menyusun } \\
\text { peta kurikulum } \\
\text { tersistematis. }\end{array}$ & $\begin{array}{l}\text { - Idea Validation } \\
\text { - Product Development } \\
\text { - Traction } \\
\text { - Business Development } \\
\text { (Scaleup, etc.) } \\
\text { - Paperwork (Financial } \\
\text { Reporting, Tax, etc.) }\end{array}$ & - Tidak ada \\
\hline $\begin{array}{l}\text { Swasta B, } \\
\text { Bandung }\end{array}$ & $\begin{array}{l}\text { - Pendanaan didapatkan } \\
\text { dari Kemenristekdikti } \\
\text { dan Kerjasama dengan } \\
\text { mitra } \\
\text { - Bidang fokus tenant } \\
\text { adalah ICT, IoT, } \\
\text { Material Baru } \\
\text { - Fase inkubasi meliputi } \\
\text { pra-inkubasi, inkubasi, } \\
\text { dan pasca inkubasi. } \\
\text { - Kurikulum disusun } \\
\text { berdasarkan fase } \\
\text { inkubasi. }\end{array}$ & $\begin{array}{l}\text { - Fase 1: Founder and } \\
\text { Team Fit, etc. } \\
\text { - Fase 2: Financial } \\
\text { Management, etc. } \\
\text { - Fase 3: Branding and } \\
\text { Marketing, etc. }\end{array}$ & $\begin{array}{l}\text { - Model bisnis } \\
\text { dengan alat } \\
\text { bantu Business } \\
\text { Model Canvas } \\
\text { - Fundraising } \\
\text { - Hukum } \\
\text { (dokumen legal } \\
\text { pengurusan } \\
\text { perusahaan) }\end{array}$ \\
\hline $\begin{array}{l}\text { Swasta C, } \\
\text { Bandung }\end{array}$ & $\begin{array}{l}\text { - Kegiatan inkubasi } \\
\text { dilakukan oleh } 3 \text { pihak. } \\
\text { - Fase seleksi meliputi } \\
\text { prestartup, nurturing } \\
\text { creativity, digital valey } \\
\text { exploration. }\end{array}$ & $\begin{array}{l}\text { - Consumer behavior, } \\
\text { business model, finance } \\
\text { and accounting), } \\
\text { Workshop, Expert } \\
\text { Session, DILo Goes to } \\
\text { Campus, DILo }\end{array}$ & $\begin{array}{l}\text { - Materi perlu } \\
\text { untuk diupdate } \\
\text { sesuai dengan } \\
\text { kebutuhan } \\
\text { tenant. }\end{array}$ \\
\hline
\end{tabular}




\begin{tabular}{|l|l|l|l|}
\hline $\begin{array}{l}\text { Inkubator } \\
\text { Bisnis }\end{array}$ & Portofolio Inkubator & Pelatihan & $\begin{array}{l}\text { Masukan } \\
\text { Wawancara }\end{array}$ \\
\hline & $\begin{array}{l}\text { Fase inkubasi } \\
\text { Fase value validation }\end{array}$ & $\begin{array}{l}\text { Festival, Startup E } \\
\text { Komunitas Gathering }\end{array}$ & \\
& & & \\
\hline
\end{tabular}

Sumber: data wawancara

\section{Tahap 2 Design}

Proses dalam tahapan ini adalah membuat rancangan modul untuk mendapatkan gambaran besar apa yang akan dituliskan lebih detil dalam modul yang selanjutnya disebut dengan framework modul. Framework ini menjelaskan struktur modul, high level konten, Setelah melakukan analisa kurikulum, dihasilkan framework modul yaitu:

\section{Gambar 2 \\ Framework Modul Kewirausahaan}

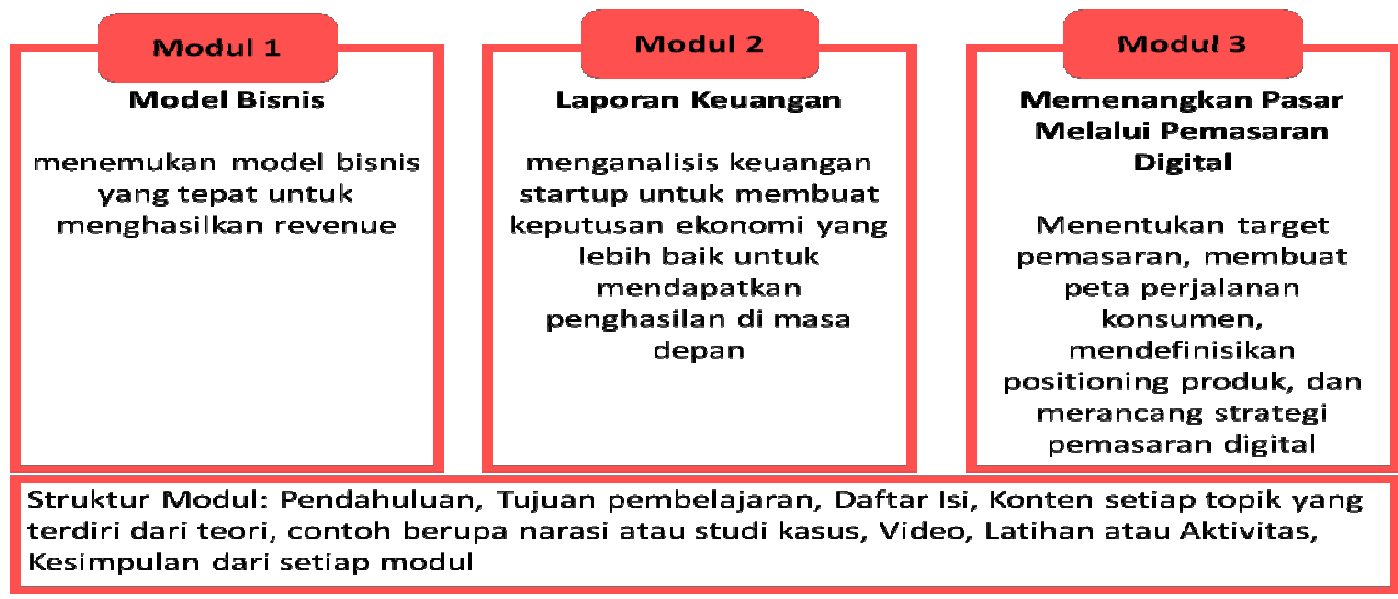

Sumber: data diolah

\section{Tahap 3 Development}

Pada tahap pengembangan, framework modul akan dikembangkan menjadi konten yang lebih detil. Modul kewirausahaan bagi tenant inkubator bisnis menjadi judul besar dimana didalamnya terdapat 3 modul yaitu, model bisnis, pemahaman keuangan, dan memenangkan pasar melalui pemasaran digital. Adapun struktur modul terdiri dari beberapa bagian yaitu sampul yang berisi judul, penulis, bulan dan tahun pembuatan, dan logo. Struktur berikutnya latar belakang yang menjelaskan fakta-fakta mengenai inkubator bisnis dan manfaat modul, tujuan pelatihan kewirausahaan yang merupakan 
bagian dari struktur, judul setiap modul, tujuan pembelajaran setiap modul, daftar isi, materi yang disajikan dalam bentuk teori, studi kasus, maupun video. Struktur berikutnya

adalah pemberian tugas yang dilakukan bersama dengan tim tenant dalam durasi tertentu. Tugas ini diberikan dengan tujuan untuk mengetahui seberapa jauh peserta tenant faham akan modul yang telah diberikan. Struktur terakhir adalah kesimpulan dari setiap modul yang berupa daftar pertanyaan yang harus dijawab oleh peserta pelatihan yang mendorong peserta untuk mengingat kembali apa yang telah dipelajari dalam bentuk diskusi aktif. Modul ini dibuat lebih atraktif dengan penjelasan ringkas supaya peserta lebih banyak berdiskusi, tanya jawab, dan berbagi pengalaman permasalahan bisnis yang mereka hadapi. Berikut merupakan modul pelatihan.

\section{Gambar 3}

\section{Modul Kewirausahaan}
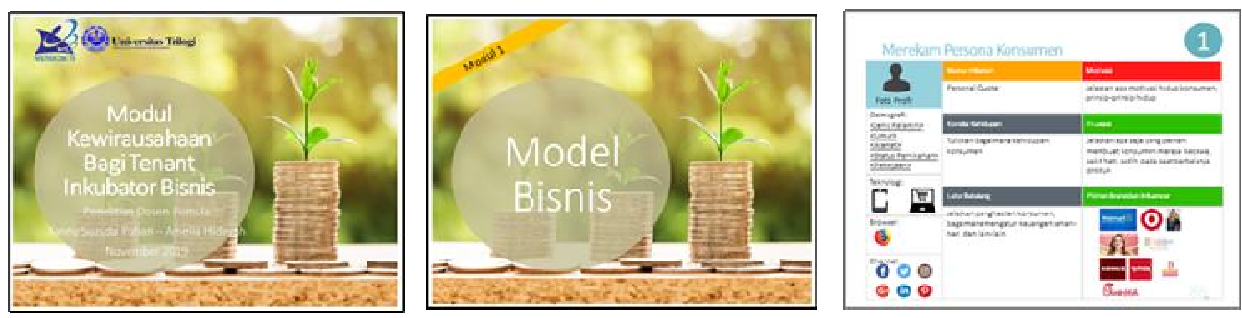

Sumber: data diolah

Selain pengembangan modul, peneliti merancang kuisioner untuk tiga pelatihan dimana peneliti meminta respon peserta mengenai penyajian kesuluruhan modul, antusiasme peserta terhadap modul, pendukung modul seperti video, dan bahasa modul.

\section{Tahap 4 Implementation}

Tahapan berikut setelah modul dibuat adalah pelatihan. Tim peneliti mengadakan pelatihan kewirausahaan pada tenant inkubator bisnis Trilogi sebanyak tiga sesi pelatihan. Jumlah tenant sebanyak 14 tenant yang fokus pada bidang makanan dan minuman, teknologi informasi, dan bidang kreatif. Sebelumnya tim peneliti mengadakan train of trainer atau ToT kepada pengajar yang akan memberikan materi langsung. Untuk model pelatihan, pengajar memberikan materi disertai video kepada para tenant dan juga memberikan tugas yang dikerjakan secara kelompok. Pelatihan berlangsung secara interaktif antara pengajar dan para tenant. Di akhir setiap sesi pelatihan, pengajar memberikan kuisioner yang harus diisi untuk meminta respon terkait pelatihan. 


\section{Tahap 5 Evaluation}

Pada tahap evaluation dilakukan analisa kuisioner modul kewirausahaan yang diberikan kepada tenant menggunakan analisa deskriptif. Profil responden tenant di Universitas Trilogi adalah 14 tim bisnis food and beverages, digital base business sebanyak 2 tim, dan creative and healthy business sebanyak 5 tim. Jumlah responden yang mengisi kuisioner berbeda-beda. Responden yang mengikuti pelatihan dan mengisi kuisioner untuk Modul Pemasaran Digital sebanyak 58 responden, 62 responden untuk Modul Model Bisnis, dan sebanyak 53 responden untuk Modul Keuangan, dengan karakteristik sebagai berikut:

Tabel 2

\section{Profil Responden}

\begin{tabular}{|l|l|l|}
\hline Jenis Modul & Jenis Kelamin & Jumlah \\
\hline $\begin{array}{l}\text { Modul Pemasaran } \\
\text { Digital }\end{array}$ & Laki-Laki & $14(24 \%)$ \\
\cline { 2 - 3 } & & \\
\hline \multirow{2}{*}{$\begin{array}{l}\text { Modul Model } \\
\text { Bisnis }\end{array}$} & Perempuan & $44(76 \%)$ \\
\cline { 2 - 3 } & Laki-Laki & $17(27 \%)$ \\
\hline Modul Keuangan & Perempuan & $45(73 \%)$ \\
\cline { 2 - 3 } & Laki-Laki & $13(25 \%)$ \\
\cline { 2 - 3 } & Perempuan & $39(75 \%)$ \\
\hline
\end{tabular}

Sumber: data diolah

Skala pengukuran variabel pada pernyataan dalam penelitian ini mengacu pada skala likert dengan menggunakan skala $1-5$. Skala tertinggi 5 menunjukkan pendapat sangat setuju sedangkan skala terendah 1 menunjukkan pendapat sangat tidak setuju. Adapun rentang skala terhadap rata-rata persepsi responden dalam kelima kategori tersebut adalah sebagai berikut :

Tabel 3

Rentang Skala Jawaban Responden

\begin{tabular}{|l|l|l|}
\hline Keterangan & \multicolumn{2}{|c|}{ Rentang skala } \\
\hline Sangan Tidak Setuju & 1 & 1.79 \\
\hline Tidak Setuju & 1.80 & 2.59 \\
\hline Agak Setuju & 2.60 & 3.39 \\
\hline Setuju & 3.40 & 4.19 \\
\hline Sangat Setuju & 4.20 & 5.00 \\
\hline
\end{tabular}

Sumber: data diolah 
Kuesioner yang diberikan terdiri dari 8 pernyataan. Data yang diperoleh dari hasil kuesioner diolah dengan menggunakan SPSS dan dianalisa deskriptif. Hasil pengolahan data sebagai berikut:

Tabel 4mHasil Pengolahan Data Kuesioner Modul Pemasaran Digital

\begin{tabular}{|c|c|c|c|c|c|}
\hline \multicolumn{6}{|c|}{ Descriptive Statistic:s } \\
\hline & $\bar{N}$ & Kinnimum & TAEKIrJIn & Vean & 5.d. Dधलadon \\
\hline $\mathrm{P}^{2}$ & 53 & 1 & 5 & 385 & 827 \\
\hline P2 & 53 & 3 & 5 & $3.7 \varsigma$ & .565 \\
\hline$\Gamma_{3}$ & 63 & 2 & 5 & 336 & 712 \\
\hline P1 & 63 & 2 & 5 & $38 \mathrm{e}$ & 739 \\
\hline P5 & 53 & 2 & 5 & 337 & .804 \\
\hline P6 & 63 & 2 & 5 & 333 & .625 \\
\hline$P 7$ & 53 & 2 & 5 & 332 & $5 \in 3$ \\
\hline P8 & 69 & 2 & 5 & $3.7 \mathrm{~s}$ & .342 \\
\hline Valid N fisssise: & 53 & & & & \\
\hline
\end{tabular}

Sumber: data diolah

Tabel 5 Hasil Pengolahan Data Kuesioner Modul Model Bisnis

\begin{tabular}{|c|c|c|c|c|c|}
\hline \multicolumn{6}{|c|}{ Descripding 5talistics } \\
\hline & $h$ & Virimum & Ka:Im」กา & h.1esn & std. DEMation \\
\hline $\mathrm{F}^{\prime}$ & 62 & 3 & 5 & 3.87 & 424 \\
\hline$\Gamma 2$ & $E 2$ & 3 & 5 & 387 & $45^{\circ}$ \\
\hline $\mathrm{P} 3$ & $E 2$ & 2 & 5 & 3.04 & .302 \\
\hline $\mathrm{FA}$ & E2 & 2 & 5 & 3.58 & 372 \\
\hline P5 & $E 2$ & 3 & 5 & 3.55 & .515 \\
\hline $\mathrm{HE}_{\mathrm{i}}$ & $\mathrm{E} 2$ & 3 & 5 & 3.32 & .559 \\
\hline Г & E? & 3 & 'י & $38 \%$ & $49:$ \\
\hline P8 & $E 2$ & 2 & 5 & 3.27 & .495 \\
\hline Valldh. (I sta1e 9 ) & $E 2$ & & & & \\
\hline
\end{tabular}

Sumber: data diolah

\section{Tabel 6 Hasil Pengolahan Data Kuesioner Modul Pemahaman Keuangan}


mengikuti pelatihan modul model bisnis setuju dengan nilai sebesar 3,68, sedangkan rata-rata responden yang mengikuti modul pemahaman keuangan setuju dengan nilai sebesar 3,62.

\section{Modul Yang Diberikan Mudah Dipahami}

Rata-rata responden yang mengikuti pelatihan menjawab setuju modul yang diberikan secara keseluruhan mudah diikuti. Rata-rata responden pelatihan modul Pemasaran Digital memberikan penilaian 3,67, pelatihan modul model bisnis memberikan penilaian 3,65 , dan pelatihan modul pemahaman keuangan memberikan nilai 3,58.

Standar deviasi tertinggi terdapat pada modul pemahaman keuangan dengan nilai sebesar 0,719, diikuti modul digital bisnis dengan nilai sebesa 0,604, dan modul model bisnis dengan nilai sebesar 0,515. Standar deviasi yang cukup tinggi pada modul pemahaman keuangan disebabkan responden kurang memahami modul.

\section{Meningkatkan Pengetahuan Atau Keterampilan}

Sebagian besar responden setuju ketiga modul ini, meningkatkan pengetahuan atau keterampilan mereka. Nilai rata-rata tertinggi diperoleh modul pemasaran digital sebesar 3,83, kemudian modul model bisni sebesar 3,82, dan modul pemahaman keuangan sebesar 3,72.

\section{Modul Ini Sangat Membantu Dalam Membantu Membangun Bisnis}

Rata-rata responden setuju modul ini sangat membantu dalam membangun bisnis mereka. Responden pelatihan modul Pemasaran Digital memberikan rata-rata penilaian sebesar 3,83, pelatihan modul model bisnis memberikan rata-rata penilaian sebesar 3,82, dan pelatihan modul pemahaman keuangan memberikan rata-rata penilaian 3,79 .

\section{Modul Ini Membantu Dalam Membuat Model Bisnis Yang Tepat}

Mayoritas responden setuju ketiga modul ini membantu dalam membuat model bisnis yang tepat. Pada modul Pemasaran Digital, responden memberikan rata-rata penilaian sebesar 3,79 dengan standar deviasi 0,642. Pada modul model bisnis, responden memberikan rata-rata penilaian sebesar 3,87, tertinggi dibandingkan modul lain dengan standar deviasi sebesar 0,495, sedangkan pada modul pemahaman keuangan rata-rata penilaian sebesar 3,77 dengan standar deviasi sebesar 0.505.

\section{KESIMPULAN}

Penyusunan modul kewirausahaan tenant inkubator bisnis perguruan tinggi menggunakan model ADDIE. Ada 5 tahapan besar yang dimulai dengan menganalisa kebutuhan pelatihan, mendesain modul, menyusun modul dan kuisioner, memberikan pelatihan kewirausahaan, dan mengevaluasi modul. Terdapat 3 modul yang disusun yaitu modul model bisnis, modul pemahaman keuangan, dan modul pemasaran digital. Untuk meningkatkan kualitas modul pemilik dokumen perlu mengevaluasi konten modul secara periodik berdasarkan 
kebutuhan dan permasalahan bisnis tenant. Kedua, kapasitas fasilitator dalam menguasai materi perlu ditingkatkan dari segi penyampaian materi, pengalaman bisnis, dan penguasaan konsep materi. Ketiga, tenant secara mandiri mempelajari modul terlebih dahulu agar proses pelatihan menjadi lebih interaktif dengan fasilitator. Keempat, penambahan topik modul sangat mungkin dilakukan mengingat topik manajemen bisnis yang masih sangat luas untuk dipelajari. Kelima, desain grafis pada modul tertentu perlu ditingkatkan seperti pada modul pemahaman keuangan.

\section{DAFTAR PUSTAKA}

Agustina, T. S. (2011). Peran Inkubator Bisnis Perguruan Tinggi Dalam Meminimalkan Resiko Kegagalan Bagi Wirausaha Baru Pada Tahap Awal (Start-Up). Jurnal Ekonomi dan Bisnis Airlangga (JEBA), Tahun XXI, No. $1,64-74$.

Aldoobie, N. (2015). ADDIE Model. American International Journal of Contemporary Research, Vol. 5, No. 6, 68-72.

Bell, R., \& Bell, H. (2016). Replicating the networking, mentoring and venture creation benefits of entrepreneurship centres on a shoestring: A student-centred approach to entrepreneurship education and venture creation. Industry and Higher Education, 30(5), 334-343.

El-Gohary, H., Selim, H. M., \& Eid, R. (2016). Entrepreneurship Education and Employability of Arab HE Business Students: An Attempt for a Primary Investigation. International Journal of Business and Social Science, 7(4), 52-72.

Ganefri and Hidayat H. (2013). Vocational Education Curriculum Perspective. Padang: Fakultas Teknik-Ind.

Hasanah, H., Malik, M. N., \& Dirawan Darma, G. (2016). Effectivenessthe Use Of Entrepreneurship Learning Module Based Tutorial Multimedia In Vocational High School. Man In India, 96(9), 3319-3326.

Heriyanto, H.S. (2018). Hilirisasi Riset, Semua PT Wajib Punya Inkubator Bisnis Teknologi. Diakses di: https://www.beritasatu.com/nasional/525832-hilirisasiriset-semua-pt-wajib-punya-inkubator-bisnis-teknologi (Diakses: 4 Desember 2018).

Hynes, B., Kennedy, N., \& Pettigrew, J. (2016). The Role of Business Schools in Framing Entrepreneurial Thinking Across Disciplines: The Case of Allied Health Professions. In Innovative Business Education Design for 21st Century Learning, Springer International Publishing, pp. 75-91. 
Jan P. Warhuus, Lene Tanggaard, Sarah Robinson, Steffen Moltrup Erno, (2017). From I to We: collaboration in entrepreneurship education and learning, Education + Training, 59(3), pp.234-249.

Liputan 6, L.P. (2019). Pengembangan Wirausaha RI Tertinggal dari Malaysia dan Thailand. Diakses di: https://www.liputan6.com/bisnis/read/4014979/pengembangan-wirausaha-ritertinggal-dari-malaysia-dan-thailand (Diakses: 17 Juli 2019).

Loi, M., Castriotta, M., \& Di Guardo, M. C. (2016). The theoretical foundations of entrepreneurship education: How co-citations are shaping the field. International Small Business Journal, 34(7), 948-971.

Mason, C. (2011). Entrepreneurship education and research: emerging trends and concerns. Journal of Global Entrepreneurship, 1(1), 13-25.

Naderi, Nahid, Saeed R. dan Ahmad R.N.I. (2013). Explaining the Role of Education Quality in University Enterpreneurship: Based on Grounded Theory. Asian Journal of Management Sciences \& Education, vol. 2 No. 4, pp. 128-135. ISSN: 21868441.

Nyello, R., Kalufya, N., Rengua, C., Nsolezi, M. J., \& Ngirwa, C. (2015). Effect of Entrepreneurship Education on the Entrepreneurial Behaviour: The Case of Graduates in the Higher Learning Institutions in Tanzania. Asian Journal of Business Management, 7(2), 37-42.

Rodríguez, R. D. Á., \& Wise, J. A. (2016). Innovation in Entrepreneurship Education: Developing Competitive Advantages for MBA Students. In Education Tools for Entrepreneurship, Springer International Publishing. pp. 199-211.

Suna Lowe Nielsen, William B. Gartner, (2017). Am I a student and/or entrepreneur? Multiple identities in student entrepreneurship, Education Training, 59(2), pp.135154.

Smaldino, Sharon E, dkk. (2012). Instructional Technology and Media for Learning Ninth Edition. New Jersey Columbus, Ohio: PEARSON Merrill Prentice Hall

Zeng, Z., \& Honig, B. (2016). How Should Entrepreneurship Be Taught to Students with Diverse Experience? A Set of Conceptual Models of Entrepreneurship Education. In Models of Start-up Thinking and Action: Theoretical, Empirical and Pedagogical Approaches, Emerald Group Publishing Limited, pp. 237-282. 
Vinokurova, N.F., Krivdina, N.V.M.Y., Badin, M.M. \& Efimova , .E. (2016). Master's Program Module "Environmental Issues - Decision Making Experience" as Precondition for Implementation of Education for Sustainable Development for Professional Training of Teachers. International Journal of Environmental and Science Education, 11(15), 8628-8636. 